\title{
Fen Bilimleri Öğretmenlerinin Laboratuvar Kullanımına Yönelik Özyeterlik İnançları: Laboratuvar Uygulamaları Programının Etkisi
}

\author{
Science Teachers' Self-Efficacy Beliefs Regarding to Use of Laboratory: \\ Effect of Laboratory Applications Program
}

DOI =http: //dx.doi. org/10.17556/jef.22252

\author{
Didem KILIÇ ${ }^{*}$, Özgül KELEŞ*, Naim UZUN ${ }^{* * *}$
}

\section{Özet}

$\mathrm{Bu}$ araştırmanın amacı, "Fen ve Teknoloji Öğretmenlerine Yönelik Laboratuvar Uygulamaları" programının, öğretmenlerin laboratuvar kullanımına yönelik özyeterlik inançlarına olan etkisinin araştııılmasıdır. Araştırmanın çalışma grubu, programa katılan 60 fen bilimleri öğretmeninden oluşmaktadır. Araştırmada değişkenler arasındaki neden-sonuç ilişkisini belirlemek amacıyla yarı deneysel araştırma modellerinden, tek grup öntest-sontest modeli izlenmiştir. Öğretmenlerin laboratuvar kullanımına yönelik özyeterlik inançlarını incelemek için "Laboratuvar Kullanımı Öz-Yeterlik Algı Ölçeği" kullanılmıştır. Yapılan analizler sonucunda öğretmenlerin özyeterlik inançlarına ilişkin öntest ve sontest puanları arasında istatistiksel olarak anlamlı bulunan fark, laboratuvar uygulamaları programının öğretmenlerin özyeterlik inançlarını arttırarak katkı sağladığını ortaya koymuştur. Araştırma sonucunda, laboratuvar uygulamalarına yönelik eğitimlerin teorik bilgi sunumundan çıkarılıp uygulamalı eğitimler şeklinde planlanması önerilmiştir.

Anahtar Sözcük: fen bilimleri öğretmenleri, laboratuvar uygulamaları, özyeterlik inanc1.

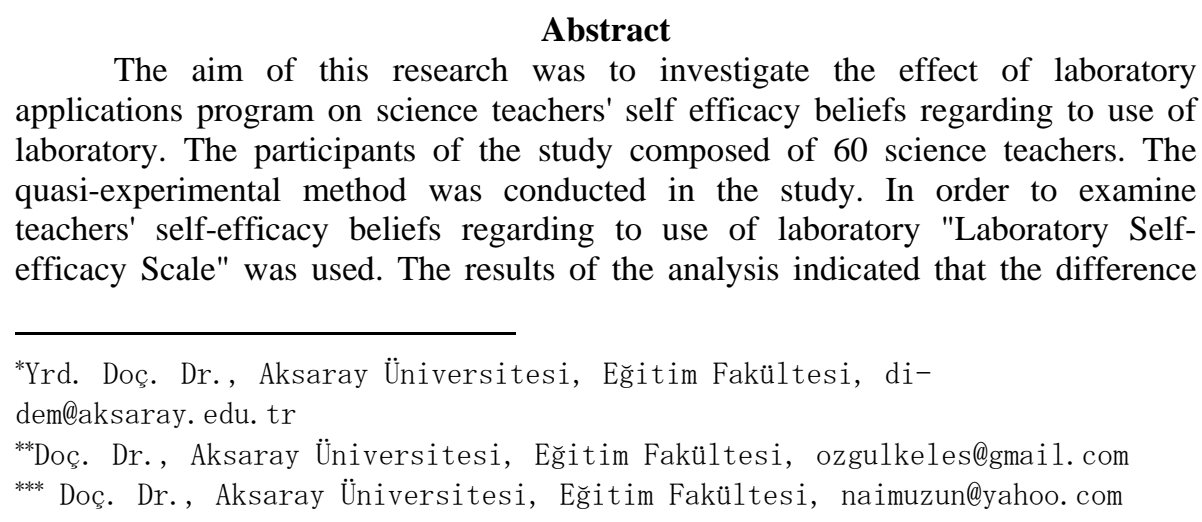

Abstract

The aim of this research was to investigate the effect of laboratory applications program on science teachers' self efficacy beliefs regarding to use of laboratory. The participants of the study composed of 60 science teachers. The quasi-experimental method was conducted in the study. In order to examine teachers' self-efficacy beliefs regarding to use of laboratory "Laboratory Selfefficacy Scale" was used. The results of the analysis indicated that the difference

*Yrd. Doç. Dr., Aksaray Üniversitesi, Eğitim Fakültesi, didem@aksaray. edu. tr

**Doç. Dr., Aksaray Üniversitesi, Eğitim Fakültesi, ozgulkeles@gmail.com

*** Doç. Dr., Aksaray Üniversitesi, Eğitim Fakültesi, naimuzun@yahoo.com 
D. Kılıç, Ö. Keleş... / Ë̈ Ĕ̆itim Fakültesi Dergisi,17(1) (2015), 218-236

between teachers' pretest and posttest scores was statistically significant. This finding revealed that the laboratory applications program has increased teachers' self-efficacy beliefs. In line with the results of the study, it can be suggested that the instructions about laboratory applications should be designed as applied practices instead of theoretical presentations.

Keywords: science teachers, laboratory applications, self-efficacy belief.

\section{Giriş}

Fen bilimleri dersinin soyut ve karmaşık kavramlardan oluşan bir içeriğe sahip olması, bu kavramların öğrenciler tarafindan anlamlı ve kalıcı biçimde öğrenilmesinde önemli yeri olan laboratuvarların etkili olarak kullanılmasını gerekli kılmaktadır. Çepni, Kaya ve Küçük'e göre (2005) fen laboratuvarları, öğrencilerin üst düzeyde kavramsal öğrenme gerçekleştirdikleri öğrenme ortamları olarak kabul edilmektedir. Laboratuvarlarda yapılan deneyler öğrencilere problem çözme, gözlem, veri toplama, yorumlama ve analiz yapma becerilerini kazandırarak bilimsel süreç becerilerini geliştirmekte böylece öğrencilerin araştırmacı ve sorgulayıcı bireyler olarak yetiştirilmesine katkı sağlamaktadır. Ekici (2009), laboratuvarların, öğrencilerin bilimle ilgili ilk elden deneyim kazanabildikleri, bilimin araştırmaya dayalı doğasını anlayabildikleri ve birlikte çalışmalar yaparak sosyal ortamlar sağlayabilme gibi pek çok becerileri kazanmalarına fırsat sağlayan bir öğrenme öğretme ortamı olduğunu vurgulamaktadır. Günümüzde izlenen yapılandırmacı yaklaşımın fen laboratuvarlarına yansımaları sonucunda öğrencilerin bilgiyi yapılandırmalarını destekleyen araştırma ve sorgulamaya dayalı laboratuvar etkinlikleri ile öğrencilerin üst düzey düşünmeleri teşvik edilmekte ve üstbiliş̧ becerilerinin gelişmesine olanak tanınmaktadır (Garnett \& Garnett, 1995).

Fen bilimleri dersi öğretim programı, öğrencilerin, kendi öğrenmesinden sorumlu olduğu, öğrenme sürecine aktif katılımının sağlandığı bilgiyi kendi zihninde yapılandırmaya olanak tanıyan araştırma ve sorgulamaya dayalı etkinliklerde bulunması görüşünü benimsemektedir (MEB, 2013). Fen laboratuvarlarında yapılan etkinlikler araştıran, sorgulayan, inceleyen, günlük hayatıyla fen konuları arasında bağlantı kurabilen bireylerin yetiștirilmesi amacına uygun öğrenme ortamları sunmaktadır. Hofstein ve Mamlok-Naaman (2007) laboratuvar deneyimlerinin, yüzyılı aşkın bir süredir, 
öğrencilerin fen kavram ve uygulamalarını anlamalarını geliştirmek, problem çözme ve bilimsel düşünme becerileri kazandırmak, bilimin ve bilim insanlarının nasıl çalıştığını anlamak, ilgi ve motivasyonu arttırmak gibi fen eğitiminin önde gelen hedeflerine katkı sağladığını vurgulamaktadırlar. Laboratuvar etkinlikleri, fen öğretimi ile hedeflenen kazanımların edinilmesinde kritik bir öneme sahip olmasına rağmen ilgili araştırma sonuçları laboratuvar kullanımının istenilen düzeyde olmadığını ortaya koymaktadır (Akkuş \& Kadayıfçı, 2007; Ayas, Çepni, \& Akdeniz, 1994; Çepni, Kaya, \& Küçük, 2005). Araştırma sonuçları genel olarak; öğretmenlerin laboratuvar uygulamaları konusunda kendilerini yeterli görmemesi, araç-gereç eksikliği, deneylerin tehlikeli olabileceği, laboratuvar ortamında sınıf kontrolünün zor olması gibi çeşitli nedenlerle laboratuvar etkinliklerine gereken önemin verilemediğini göstermektedir (Aydoğdu, 1999; Güneş, Şener, Topal Germi, \& Can, 2013; Kocakülah \& Savaş, 2011; Uluçınar, Cansaran, \& Karaca, 2004). Böyük, Demir ve Erol (2010) tarafından yapılan araştırmada ögretmenlerin, laboratuvarların fen bilimleri öğretimindeki önemini bildikleri ancak bununla beraber laboratuvarlardaki araç gereçleri tanıma ve kullanma konusunda kendilerini yetersiz ve kısmen yeterli gördükleri sonucuna ulaşılmıştır. Benzer şekilde, yapılan çalışmalarda ögretmenlerin laboratuvar uygulamalarına yeterince ya da hiç yer vermedikleri, öğretmenlerin laboratuvar uygulamaları konusunda kendilerini yetersiz hissettikleri belirlenmiştir (Şeker, Yalçın, \& Yurdanur Altunay, 2006).

Fen bilimleri öğretmenlerinin, derslerinde laboratuvar etkinliklerine gereken önemi göstermelerinde, kendilerini yeterli görmelerine ilişkin inançları etkili olmaktadır. Kişilerin kendilerini güvenli ve yeterli hissettikleri işleri yapma, kendilerini yeterli hissetmedikleri işlerden kaçma eğilimi gösterdikleri ifade edilmektedir (Kurbanoğlu, 2004). Kişinin bir işi yapabilecek beceriye sahip olmasına rağmen bunu yapabileceği konusunda kendine özgüveni yoksa yapamayabileceği ve başarısız olabileceği vurgulanmaktadır (Büyüköztürk, 2011; Ekici, 2009; Kurbanoğlu, 2004). Kişinin bir işi yapmak için gerekli becerilere sahip olduğu konusundaki inanc1, özyeterlik inancı olarak tanımlanmaktadır (Bandura, 1994). Bandura'ya göre özyeterlik, kişinin sahip olduğu yetenekler ile değil, 
kişinin sahip olduğu yetenek ile bir işi yapabileceğine dair inançları ile ilgilidir (Çalışkan, Selçuk, \& Özcan, 2010). Bireyin yetenekleri ile ilgili inançlarına dayanan özyeterlik, amaca ulaşmak için yapılması gerekenlerin yerine getirilmesi ve organize edilmesinde kişinin kendi yapabileceklerine ilişkin inancıdır (Bandura, 1995). Kişilerin istedikleri sonucu alacaklarına inanmadıkları sürece harekete geçmek konusunda isteksiz davrandıkları, sonuç olarak kişilerin özyeterlik inançlarının, seçimlerinde etkili olduğu belirtilmektedir (Kurbanoğlu, 2004). Olumlu özyeterlik inancına sahip kişilerin, isteyerek harekete geçtikleri, güçlükler karşısında daha dayanıklı ve ısrarcı oldukları, daha az stresle daha başarılı oldukları gözlenirken; olumsuz özyeterlik inancına sahip kişilerin, eylemden kaçındıkları, yapılan bir işi sonuçlandırmadan bırakabildikleri, daha fazla stresle daha düşük performans gösterdikleri bildirilmektedir (Kurbanoğlu, 2004; Y1lmaz, Gürçay, \& Ekici, 2007).

Yapılan araştırmalar deneyimin, özyeterliği etkileyen en önemli faktörlerden biri olduğunu ve olumlu deneyimlerin özyeterlik algısının güçlenmesini sağladığını göstermektedir (Bandura, 1986; Kurbanoğlu, 2004). Bandura (1977), özyeterlik inançlarının dört temel kaynağ olduğunu belirtmektedir: (1) Performans Başarıları: Kişinin kendi deneyimlerine dayandığ 1 için, özyeterlik üzerinde en etkili olan faktör kişinin göstermiş olduğu kendi performansıdır. Başarılı deneyimler özyeterlik inancını artırırken, üst üste yaşanan başarısızlıklar özyeterlik inancının düşmesine neden olur. (2) Dolaylı Deneyimler: Bireyin başkalarının başarılı ya da başarısız etkinliklerini görmesi, aynı etkinlikleri kendisinin de başarabileceğine ya da başaramayacağına ilişkin yargısını güçlendirir. Diğer bir ifade ile, kişiler başkalarının deneyimlerinden yola çıkarak da özyeterlik inancı geliştirirler. (3) Sözel İkna: Kişinin başarabileceğine ya da başaramayacağına ilişkin sözler, teşvikler ve öğütler değişik ölçülerde özyeterlik algısını etkiler. Bir işi yapabilecek kapasitede olduğu konusunda dışarıdan gelen bir değerlendirmenin özyeterlik inancı üzerindeki etkisi çok güçlü olmamakla beraber kişinin işi yapmak konusunda göstereceği çabayı olumlu yönde etkilediği bilinmektedir. (4) Duygusal Durum: Herhangi bir eyleme karşı kişinin deneyimlediği heyecan, stres, korku gibi güçlü duygular, sonucun başarılı veya başarısız olacağı konusunda ipuçları sağlar. Olumlu duygular, 
özyeterlik inancını güçlendirirken, olumsuz duygular özyeterlik inancını zayıflatır, daha fazla stres ve heyecan yaratır ki bu da sonuçta performansı olumsuz yönde etkiler (Çalışkan, Selçuk, \& Özcan, 2010; Kurbanoğlu, 2004; Yılmaz, Gürçay, \& Ekici, 2007).

Ekici'ye göre (2009), özyeterlik inancı düșük olan bir kișinin başarı düzeyinin yüksek olması beklenilmemeliyken, yüksek düzeyde özyeterlik inancına sahip bir kişinin de başarı düzeyinin düşük olacağı düşünülmemelidir. Ancak insan davranışlarını etkileyen tek faktörün özyeterlik inancı olduğu ve kişinin ilgili alanda güçlü özyeterlik inanc1 olmasının bir işi yapması için yeterli olduğu anlamı çıkarılmamalıdır (Kurbanoğlu, 2004). Bununla birlikte özyeterliğin, davranışı başlatan, güdülenmeyi ve devamlılığ sergilenmesini ve tekrarlanmasını sağlayan bir rol oynadığı bilinmektedir (Kotaman, 2008). Buna göre, öğretmenlerin başarılı olabilmelerinde pek çok faktörün yanı sıra yüksek düzeyde özyeterlik inancına sahip olmanın etkili olacağı ifade edilebilir. Dolayısı ile öğretmenlerin laboratuvar etkinliklerini etkili ve başarılı olarak gerçekleştirebilmeleri için laboratuvar kullanımına yönelik özyeterlik inançlarının yüksek olması gerekliliği dikkate alınması gereken önemli bir durum olarak ortaya çıkmaktadır. Laboratuvar kullanımına yönelik özyeterlik algısı Ekici (2009) tarafından, kişinin laboratuvarı uygun biçimde kullanma konusunda kendine ilişkin yargısı olarak tanımlanmaktadır.

Öğretmenlerin laboratuvar kullanımına yönelik kendilerini yetersiz hissetmeleri ve dolayısı ile derslerinde laboratuvar etkinliklerine yeterince yer vermemelerinin bir diğer önemli nedeni olarak öğretmenlerin laboratuvar kullanımına yönelik hizmet öncesi eğitimlerinin yetersiz oluşu gösterilmektedir. Araştırma sonuçları, öğretmenlerin laboratuvar ve araç-gereç kullanımı, deneylerin uygulanması, öğrencilerine deneylerin yaptırılması gibi konularda aldıkları hizmet öncesi eğitimlerin farklılık göstermekle beraber yetersiz kaldığını ortaya koymaktadır (Böyük, Demir, \& Erol, 2010; Nakiboğlu \& Sarıkaya, 2000; Uluçınar, Cansaran, \& Karaca, 2004). Hizmet öncesi eğitim sürecinde laboratuvar uygulaması için gerekli bilgi ve beceriyi kazanamayan öğretmenlerin, görevlerinde yetersiz bir laboratuvar ortamıla karşılaştıklarında deney yapmada zorluk çektikleri belirlenmiştir (Uluçınar, Cansaran, \& Karaca, 2004). 
Dikkati çeken sonuçlardan bir diğeri de öğretmenlerin, hizmet öncesi eğitimlerinde gerçekleştirilen laboratuvar etkinliklerinin ilköğretim ve ortaöğretim programlarında yer alan laboratuvar etkinliklerinden farklı olması nedeniyle yetersiz hissetmeleridir (Nakiboğlu \& Sarıkaya, 2000). Öğretmenlerin laboratuvar kullanımına yönelik hizmet öncesi eğitimlerine ilişkin ortaya konulmuş bu sonuçların yanı sıra, görevleri süresince öğretim programlarında meydana gelen değişiklikler de öğretmenlerin laboratuvarları etkin olarak kullanmalarını güçleştiren bir diğer faktör olarak ortaya çıkmaktadır (Uluçınar, Cansaran, \& Karaca, 2004).

Öğretim programlarında meydana gelen değişimler, izlenmesi gereken laboratuvar yaklaşımlarında da yenilikleri beraberinde getirmektedir. Öğretmenler bu değişimin gerisinde kalmamak ve yenilikleri takip edebilmek için kendilerini bu konularda geliştirecek çalışmalara ihtiyaç duymaktadır. $\mathrm{Bu}$ bağlamda fen bilimleri öğretmenlerinin laboratuvar yaklaşımlarındaki yeniliklerden haberdar edilmesi, bilgilerinin güncellenmesi ve laboratuvar kullanma becerilerinin geliştirilmesi önem kazanmaktadır. Öğretmenleri laboratuvar uygulamalarındaki yeni yaklaşımlar konusunda bilgilendirmek, laboratuvar kullanımını artırmaya teşvik etmek, araçgereç kullanım becerilerini geliştirmek, motivasyonlarını artırmak ve özgüven kazandırmak amacıyla gerçekleştirilecek bir etkinlik programı, öğretmenlerin bilgi, beceri ve güven kazanmalarını sağlayacaktır. Ayrıca belirtilen içerikteki bir etkinlik programının, öğretmenlerin laboratuvar kullanımına yönelik özyeterliklerini arttıracağı varsayımıyla, çalışmada, laboratuvar uygulamaları içeren bir etkinlik programının, öğretmenlerin laboratuvar kullanımına yönelik özyeterlik inançlarına etkisi olup olmadığı konusu araştırılmıştır.

Laboratuvar uygulamaları programının kapsamı ve içeriği, fen bilimleri dersi öğretim programının temellerine dayanarak, Milli Eğitim Bakanlığı'nca belirlenen konu alanı ve öğrenme alanlarına yönelik kazanımlar dikkate alınarak oluşturulmuştur. Fen bilimleri dersi öğretim programında benimsenen araştırma ve sorgulamaya dayalı öğrenme; öğrencilerin birer bilim insanı gibi yaparak, yaşayarak, düşünerek bilgiyi kendi zihninde oluşturduğu öğrenci merkezli bir yaklaşımdır (MEB, 2013). Öğretmenlerin araştırma ve 
sorgulamaya dayalı öğrenme sürecini etkili olarak yürütebilmeleri, laboratuvar olanaklarından faydalanabilmeleri ve fen deneylerini etkin olarak gerçekleştirebilmeleri ile mümkündür. $\mathrm{Bu}$ da öncelikli olarak öğretmenlerin laboratuvar kullanımına yönelik özyeterliklerinin yüksek olmasını gerektirmektedir. Öğretmenlerin laboratuvar kullanımına yönelik özyeterlik inançlarını arttıramaya olanak tanıyacak etkinlik programlarının, daha nitelikli fen öğretimi için öğretmenlere destek sağlayacağı gerekçesiyle gerçekleştirilen bu çalışmanın sonuçlarının öğretmenlerin laboratuvarları etkin olarak kullanımını arttırmada önemli katkılar sağlayacağı düşünülmektedir. Bununla beraber bu çalışmanın, öğretmenlerin laboratuvar kullanımına yönelik özyeterlik inançları konusunda gerçekleştirilen çok az sayıdaki araştırma sonucunun genişletilmesi bakımından önemli olduğu düşünülmektedir.

\section{Araştırmanın Amacı}

$\mathrm{Bu}$ çalışmada, "Fen ve Teknoloji Öğretmenlerine Yönelik Laboratuvar Uygulamaları" başlıklı etkinlik programının, öğretmenlerin laboratuvar kullanımına yönelik özyeterlik inançlarına olan etkisinin araştırılması amaçlanmaktadır. Bu amaçla araştırmada, 'uygulanan program sonrasında öğretmenlerin laboratuvar kullanımına yönelik özyeterlik inançları anlamlı bir farklılık göstermekte midir?' sorusuna yanıt aranmıştır.

\section{Yöntem}

Araştırmada değişkenler arasındaki neden-sonuç ilişkisini belirlemek amacıyla yarı deneysel araştırma modellerinden, tek grup öntest-sontest modeli izlenmiştir. Çalışmaya konu olan programın, amaç ve içeriği doğrultusunda tek grup halinde uygulanması gerekliliği nedeniyle seçilen bu modele uygun olarak laboratuvar uygulamaları programının, öğretmenlerin laboratuvar kullanımına yönelik özyeterlik inançları üzerindeki etkisi incelenmiştir. Araştırma modeli gereğince, çalışmada gerçekleştirilen program uygulamasının öncesinde (öntest) ve sonrasında (sontest) öğretmenlerin laboratuvar kullanımına yönelik özyeterlik inançlarına ilişkin elde edilen veriler üzerinde değerlendirmeler gerçekleştirilmiştir. 
D. Kılıç, Ö. Keleş... / Ë̈U Eğitim Fakültesi Dergisi,17(1) (2015), 218-236

\section{Çalışma Grubu}

Çalışma grubu, "Fen ve Teknoloji Öğretmenlerine Yönelik Laboratuvar Uygulamaları" programına katılan 60 fen bilimleri öğretmeninden oluşmaktadır. Öğretmenler, Türkiye'nin 20 farklı ilinde Milli Eğitim Bakanlığı'na bağlı olarak görev yapmaktadırlar. Öğretmenlerin seçiminde dikkate alınan kriterler, laboratuvar uygulamaları programının amaçları doğrultusunda araştırmacılar tarafindan belirlenmiş ve oluşturulan başvuru formunda belirlenen kriterlere yönelik veri elde etmek amacıyla açık uçuk sorulara yer verilmiştir. Başvuru formu ile katılımcı adaylarından kişisel bilgileri, mesleki bilgileri ve eğitim bilgilerinin yanı sıra derslerinde laboratuvarlardan aktif olarak faydalanıp faydalanmadıkları, nedenleri, laboratuvar etkinlikleri sırasında karşılaştıkları sorunların neler olduğuna yönelik veri toplanmıştır. Başvuru formları katılımcı adaylarının ifadeleri doğrultusunda ilgi ve ihtiyaçları göz önünde bulundurularak, ayrıca mezuniyet alanları, meslekteki hizmet süreleri ve görev yaptıkları il ve ilçeler dikkate alınarak değerlendirilmiştir. Programa gönüllü olarak katılmak için başvuru yapan öğretmenlerin görev yerlerine göre değerlendirilmesi yapılırken, çalıştıkları kurumların Türkiye'nin farklı bölgelerinden il ve ilçeler olmasını sağlamak amaciyla başvuru yapılan her ilden en az bir öğretmen programa katılmak üzere belirlenmiştir. Bu iller; Aksaray, Ankara, Ağr1, Batman, Erzurum, Giresun, Hatay, İstanbul, İzmir, Kayseri, Kirşehir, Konya, Mardin, Mersin, Nevşehir, Niğde, Sakarya, Rize, Yalova ve Zonguldak olup, Türkiye'nin yedi farklı bölgesinden başvuru oranı doğrultusunda seçimler gerçekleştirilmiştir.

Sonuç olarak katılımcı öğretmenlerin programa kabul edilmesinde, laboratuvar kullanımında ve öğretim programına uygun deney uygulaması yapmakta zorlanan; lisans mezuniyet alanı fen bilimleri, fizik, kimya ve biyoloji öğretmenlikleri olan adaylar tercih edilmiştir. Programa katılmak için başvuran 261 fen bilimleri öğretmeni arasından belirtilen kriterlere göre seçilen 60 öğretmen bu araştırmanın çalışma grubunu oluşturmuştur. Çalışma grubunda yer alan öğretmenlerin demografik özellikleri, Tablo l'de sunulmuştur. 
D. Kılıç, Ö. Keleş... / Ë̈U Eğitim Fakültesi Dergisi,17(1) (2015), 218-236

\begin{tabular}{llcc}
\hline \multicolumn{3}{l}{ Tablo 1. Çalışma Grubunu Oluşturan Öğretmenlerin Demografik Özellikleri } \\
\hline Demografik Özellikler & & f & \% \\
\hline \multirow{2}{*}{ Cinsiyet } & Kadın & 30 & 50,0 \\
& Erkek & 30 & 50,0 \\
\hline \multirow{4}{*}{ Kıdem yılı } & $01-04$ & 24 & 40,0 \\
& $05-09$ & 16 & 26,7 \\
& $10-14$ & 13 & 21,7 \\
& $15-19$ & 5 & 8,3 \\
& $>20$ & 2 & 3,3 \\
\hline \multirow{3}{*}{ Mezuniyet programı } & Fen Bilimleri Öğretmenliği & 43 & 71,7 \\
& Biyoloji Öğretmenliği & 8 & 13,3 \\
& Fizik Öğgretmenliği & 4 & 6,7 \\
Toplam & Kimya Öğretmenliği & 5 & 8,3 \\
\hline & & 60 & 100,0 \\
\hline
\end{tabular}

\section{Uygulama}

"Fen ve Teknoloji Öğretmenlerine Yönelik Laboratuvar Uygulamaları" isimli etkinlik programı, TÜBİTAK desteği ile Aksaray Üniversitesi'nde ayrı dönemlerde olmak üzere üç defa gerçekleştirilmiştir. Fen bilimleri dersi öğretmenlerini laboratuvar uygulamalarındaki yeni yaklaşımlar konusunda bilgilendirmek, laboratuvar kullanımını artırmaya teşvik etmek, araç-gereç kullanım becerilerini geliştirmek, motivasyonlarını artırmak ve özgüven kazandırmak amacıyla gerçekleştirilen programda 13 bilim kurulu üyesi, 17 eğitmen, 6 yardımcı personel ve 2 teknisyen görev almıştır. Program kapsamında fen bilimleri dersi öğretim programında yer alan laboratuvar deneyleri, çeşitli üniversitelerin eğitim fakülteleri ve fen edebiyat fakültelerinde görev yapan, laboratuvar uygulamaları programının amaç ve içeriğine uygun çalışma alanları olan öğretim üyeleri tarafından uygulamalı olarak gerçekleştirilmiştir. 5 günlük program süresince, fen bilimleri dersi öğretim programına uygun olarak toplam 44 laboratuvar deneyi 36 ders saatinde uygulanmıştır. $\mathrm{Bu}$ deneylerin 17 tanesi "Fiziksel Olaylar", 12 tanesi "Canlılar ve Hayat", 13 tanesi "Madde ve Değişim" ve 2 tanesi "Dünya ve Evren" öğrenme alanlarına uygun olarak hazırlanmıştır. Deneylerin öncesinde gerekli teorik bilgiler eğitmenler tarafından kısaca sunulmuş, ardından deneyin içeriğine göre öğretmenlerin bireysel veya grup çalışması şeklinde katılımı ile pratik uygulamalar gerçekleştirilmiştir. 
Etkinlikler planlanırken, öğretmenlerin araç-gereç eksikliği nedeniyle gerçekleştirmede güçlük yaşayabilecekleri etkinlikler dikkate alınarak, temini kolay, maliyeti düşük, basit araç-gereçlerle de gerçekleştirilebilecek deneylere yer verilmiştir. Ayrıca öğretim programı kapsamında yer alan deneyler, program kapsamında çeşitlendirilmiş böylece öğretmenlere derslerinde uygulayabilecekleri laboratuvar etkinlikleri için alternatif seçenekler sunulmuştur. Etkinlik programı kapsamındaki uygulamalar, fen bilimleri dersi öğretim programında benimsenen öğrenme modelleri doğrultusunda gerçekleştirilerek öğretmenlerin yeni yaklaşımlar konusunda bilgi, beceri ve özgüven kazanmaları hedeflenmiştir. Programdaki öğretim etkinliklerinin tamamlanmasının ardından laboratuvar uygulamaları programının genel değerlendirmesinin yapılması amacıyla hazırlanan değerlendirme formları katılımc1 öğretmenler tarafından doldurulmuştur. Değerlendirme formunda öğretmenlerden program hakkındaki görüşlerinin yanı sıra konaklama, ulaşım ve yemek hizmetleri konusundaki görüşleri de alınmıştır. Ayrıca programın sonunda bilim kurulu üyeleri, eğitmenler, personel ve öğretmenlerin katılımıyla değerlendirme toplantısı gerçekleştirilmiş ve bu toplantıda bütün grubun katıldığı bir tartışma ortamı oluşturularak katılımcıların görüşleri değerlendirilmiştir.

\section{Verilerin Toplanmast}

Katılımcı öğretmenlerin laboratuvar kullanımına yönelik özyeterlik inançlarını incelemek için Ekici (2009) tarafından öğretmenlere yönelik olarak geliştirilen "Laboratuvar Kullanımı ÖzYeterlik Alg1 Ölçeği" kullanılmıştır. Ölçek, laboratuvar uygulamaları programının başlamasından önce ve uygulamaların tamamlanmasından sonra olmak üzere katılımcı öğretmenlere öntest ve sontest olarak uygulanmıştır.

Laboratuvar Kullanımı Öz-Yeterlik Alg1 Ölçeği, 5'li likert tipinde toplam 18 maddeden oluşmaktadır. Ölçekten alınabilecek en düşük puan 18, en yüksek puan 90'dır. Ölçeğin geçerlik ve güvenirlik analizlerinden elde edilen bulguların psikometrik özellikler bakımından anlamlı ve kabul edilir düzeyde olduğu sonucuna ulaşılmıştır (Ekici, 2009). Faktör analizi sonucuna göre iki faktörlü bir yap1 gösteren ölçek, Kişisel Faktörler ve D1ş Faktörler (Öğrenci- 
Ortamdan kaynaklanan faktörler) olmak üzere iki boyuttan oluşmaktadır. Çalışmada, ölçeğe ilişkin bulunan iki faktörün, toplam varyansın \%46,74'ünü açıkladığı belirlenmiştir. Yap1 geçerliği kapsamında ölçeğin hesaplanan KMO (Kaiser-Meyer-Olkin) değeri 0,633 olarak belirlenmiş olup Barlett Testi değeri $(630,236)$ 0,001 düzeyinde anlamlı bulunmuştur. Ölçeğin geneline ilişkin olarak hesaplanan güvenirlik katsayısı $\alpha=0,90$ olarak rapor edilmiştir (Ekici, 2009). Bu çalışmada ölçeğin geneline ilişkin olarak Cronbach alfa katsayısı ile hesaplanan güvenirlik değeri 0,87 olarak bulunmuştur.

\section{Verilerin Analizi}

Çalışmada toplanan veriler düzenlendikten sonra istatistiksel analizleri SPSS 15.0 programı kullanılarak gerçekleştirilmiştir. Çalışma grubunun genel özelliklerinin belirlenmesinde betimsel istatistik değerleri hesaplanmıştır. Fen bilimleri öğretmenlerinin laboratuvar kullanımına yönelik özyeterlik inançlarının, uygulama sonrasında öncesine göre farklılaşıp farklılaşmadığını belirlemek üzere, ortalama puanlar arasındaki farkın anlamlılığını test etmede kullanılan, bağımlı gruplar için t-testi gerçekleştirilmiştir. Etki büyüklüğü için Cohen $\mathrm{d}$ değeri hesaplanarak rapor edilmiştir. Tüm ölçümler için anlamlılık düzeyi 0,001 olarak değerlendirilmiştir.

\section{Bulgular}

Öğretmenlerin özyeterlik inançları öntest ve sontest puanlarına ait betimsel istatistik değerleri incelendiğinde puanların, çarpıklık (ÇK) ve basıklık katsayılarına (BK) göre normal dağılımdan sapma göstermediğini söylemek mümkündür $\left(\right.$ ÇK $_{\text {(Öntest) }}=0,069$ ve ÇK $\mathrm{C}_{\text {(Sontest) }}$ $=-0,081 ;-1<$ ÇK $<1 ; \mathrm{BK}_{\text {(Öntest) }}=-0,488$ ve $\mathrm{BK}_{\text {(Sontest) }}=-0,506 ;-1<$ BK < 1). Bununla beraber normallik varsayımını test etmek için gerçekleştirilen Kolmogorov-Smirnov testi sonuçları, öntest ve sontest fark puanları dizisi için $0,105, p=0,100 ; p>0,05$ olarak belirlenmiş olup, verilerin normallik varsayımını sağladığı tespit edilmiştir. Öğretmenlerin öntest ve sontest puanlarına ait betimsel istatistik değerleri Tablo 2'de sunulmuştur. 
D. Kılıç, Ö. Keleş... / Ë̈U Eğitim Fakültesi Dergisi,17(1) (2015), 218-236

Tablo 2. Öğretmenlerin Laboratuvar Kullanımına Yönelik Özyeterlik İnançlarına İlişkin Betimsel İstatistikler

\begin{tabular}{lccccc}
\hline & $\bar{x}$ & SS & Varyans & Min & Max \\
\hline Öntest & 73,73 & 8,099 & 65,589 & 56,00 & 90,00 \\
Sontest & 79,35 & 6,671 & 44,503 & 64,00 & 90,00 \\
\hline
\end{tabular}

Laboratuvar uygulamaları programına bağlı olarak, öğretmenlerin özyeterlik inançlarına ilişkin öntest $(\bar{X}=73,73)$ ve sontest puanları ortalamaları ( $\overline{\mathrm{X}}=79,35)$ arasında 5,62 puanlık bir fark oluştuğu Tablo 2'de görülmektedir. Bu farkın istatistiksel olarak anlamlılığını test etmek üzere bağımlı gruplar için t-testi gerçekleştirilmiş ve sonuçları Tablo 3'de sunulmuştur.

Tablo 3. Öğretmenlerin Laboratuvar Kullanımına Yönelik Özyeterlik İnançları Öntest ve Sontest Puanlarının Bağımlı Gruplar İçin t-Testi Sonuçları

\begin{tabular}{|c|c|c|c|c|c|c|c|}
\hline \multicolumn{2}{|c|}{ Değişken } & \multirow{2}{*}{$\begin{array}{l}\mathbf{N} \\
60\end{array}$} & \multirow{2}{*}{$\begin{array}{c}\bar{x} \\
73,73 \\
\end{array}$} & \multirow{2}{*}{$\begin{array}{c}\text { SS } \\
8,098 \\
\end{array}$} & \multirow{3}{*}{$\begin{array}{c}\text { sd } \\
59\end{array}$} & \multirow{3}{*}{$\frac{\mathbf{t}}{-4,374}$} & \multirow{3}{*}{$\begin{array}{c}\mathbf{p} \\
, 000^{*}\end{array}$} \\
\hline Özyeterlik İnanç & Öntest & & & & & & \\
\hline Puanlart & Sontest & 60 & 79,35 & 6,671 & & & \\
\hline
\end{tabular}

Yapılan analizler sonucunda öğretmenlerin özyeterlik inançlarına ilişkin öntest ve sontest puanları arasındaki fark, istatistiksel olarak anlamlı bulunmuştur $\left(\mathrm{t}_{(59)}=-4,374 ; \mathrm{p}<0,001\right)$. Belirlenen bu farkın etki büyüklük değeri Cohen $d=0,56$ olarak hesaplanmıştır. $\mathrm{Bu}$ değer orta düzeyde bir etki büyüklüğü olarak yorumlanmaktadır (Cohen, 1988). Bu sonuçlara dayanarak, laboratuvar uygulamaları programının, öğretmenlerin özyeterlik inançlarına ilişkin puanlarını arttırarak katkı sağladığı söylenebilir.

\section{Sonuç ve Tartişma}

$\mathrm{Bu}$ araştırmada, laboratuvar uygulamaları programı kapsamında gerçekleştirilen etkinliklerin, fen bilimleri öğretmenlerinin laboratuvar kullanımına yönelik özyeterlik inançları üzerindeki etkisi araştırılmıştır. Analiz sonuçları, laboratuvar uygulamaları programının, öğretmenlerin laboratuvar kullanımına yönelik özyeterlik inançlarına ilişkin test puanlarını arttırarak katkı sağladığını 
göstermiştir. Çalışmaya katılan öğretmenlerin laboratuvara yönelik özyeterlik inançlarının, laboratuvar uygulamaları programı sonunda program öncesine göre yükseldiği sonucuna ulaşılmıştır.

Laboratuvar uygulamaları programı kapsamında öğretmenlerin hem bireysel hem de küçük gruplar şeklinde bir arada çalışması sağlanarak, öğrenci merkezli yaklaşım doğrultusunda uygulamalar gerçekleştirilmiş ve öğretmenlerin laboratuvarları daha etkin ve verimli kullanma davranışlarını artırmak hedeflenmiştir. Bu hedef, davranış değişikliğinin belirleyicilerinden biri olan özyeterlik inanc1 ile doğrudan ilişkilidir. Programı süresince, öğretmenlerin deney malzemelerini daha yakından tanımalarına, her öğretmenin bu malzemelerin kullanımını öğrenmesine ve deneyleri hem bireysel hem de grup çalışmalarıyla gerçekleştirmelerine firsat sağlanarak laboratuvar kullanımına yönelik özyeterlik inançlarının artırılması sağlanmıştır. Öğretmenlerin lisans eğitimlerinden sonra gelişen teknoloji ve değişen öğrenme stratejileri konusunda yeni deneyimler kazanmalarına firsat sağlanmıştır. Yapılan araştırmalar özyeterliği etkileyen en önemli faktörlerden birinin deneyim olduğunu ve olumlu deneyimlerin özyeterlik algısının güçlenmesini sağladığını göstermekte ve bu araştırmanın sonuçlarını desteklemektedir (Bandura, 1986, s. 395; Delcourt \& Kinzie, 1993).

Çalışmada elde edilen verilerin analizi sonucunda öntest ve sontest puanları arasındaki farkın anlamlı bulunması, laboratuvar uygulamaları programı sonrasında öğretmenlerin deneyleri gerçekleştirme kapasiteleri konusunda özyeterlik inançlarının güçlendiğini göstermiştir. İlgili araştırmalar, kişilerin çeşitli eylemleri gerçekleştirdiği, bu eylemlerin sonuçlarını değerlendirdiği, değerlendirme sonuçlarını benzer eylemleri gerçekleştirme kapasiteleri konusunda bir yeterlik inancı geliştirmekte kullandıklarını ve geliştirdikleri inanca göre hareket ettiklerini göstermektedir (Bandura, 1986; Kurbanoğlu, 2004).

Laboratuvar kullanımı ve özyeterlik inancı ile ilgili yapılan araştırmalar incelendiğinde özyeterliğin, üzerinde önemle durulması gereken bir psikolojik değişken olduğu vurgulanmaktadır (Yaman, Koray, \& Altunçekiç, 2004). Fizik öğretmenlerinin lise fizik programındaki deneyleri yapamadıklarının belirlendiği bir çalışmada; laboratuvarlardaki araç-gereçlerden bazılarını tanımamaları ve 
bunların nasıl kullanıldığını bilmemeleri, bazı deneyleri zor olarak nitelendirmeleri ve onların yapılışı ile ilgili özgüvene sahip olmamaları gibi faktörlerin etkili olduğu ortaya çıkmıştır (Çepni, Kaya, \& Küçük, 2005). Bu çalışmanın sonucunda ise görülmüştür ki, öğretmenlerin laboratuvar araç-gereçlerini tanımalarına ve kullanmalarına olanak sağlandığında laboratuvarı kullanmaya yönelik özyeterlik inançları artmaktadır. Laboratuvar malzemelerini tanıma ve kullanmanın özyeterlik inancına olan olumlu etkisini destekleyen bir diğer çalışmada animasyon ve simülasyon programı kullanımının fen bilgisi öğretmen adaylarının fizik dersine karşı özyeterlik inançlarına etkisi araştırılmış ve yalnızca animasyon ve simülasyon destekli öğrenme yöntemleri laboratuvar için tek başına kullanıldığında öğrencilerin özyeterlik inançlarını değiştirmezken; laboratuvar malzemeleri kullanılarak deney yapan grubun özyeterlik inançlarının anlamlı olarak arttığı sonucuna ulaşılmıştır (Yener, Aydın, \& Köklü, 2012). Ekici (2009) tarafından yürütülen araştırmada ise biyoloji öğretmenlerinin laboratuvara yönelik özyeterlik inançları incelenmiş ve orta düzeyde olduğu sonucuna ulaşılmıştır. Laboratuvar derslerinin yapılmaması bu sonucun nedenleri arasında gösterilmiştir. Bu sonuç, laboratuvar kullanımının öğretmenlerin özyeterlik inançlarına etkisini ortaya koyan bu çalışmanın sonucunu destekler nitelikte bulunmuştur.

Sonuç olarak, fen bilimleri dersi öğretmenlerinin laboratuvar uygulamalarını etkili olarak gerçekleştirmelerinin, fen eğitiminin hedefleri bakımından çok önemli olduğu bir gerçektir. Bu durum, fen bilimleri öğretmenlerinin laboratuvar kullanma becerilerinin geliştirilmesi ve bilgilerinin güncellenmesi gerekliliğini doğurmaktadır. Araştırmadan elde edilen sonuçlar doğrultusunda fen bilimleri öğretmenlerine, laboratuvar uygulamalarındaki yeni yaklaşımların ve basit malzemelerle yapılabilecek deneylerin öğretilmesi için hazırlanan TÜBİTAK destekli programların sürekli hale getirilmesinin önemli katkılar sağlayacağı ifade edilebilir. Bu eğitimler teorik bilgi sunumundan çıkarılıp uygulamalı etkinlikler şeklinde planlandığında, öğretmenlerin laboratuvar kullanımına yönelik özyeterlik inançlarını olumlu yönde etkilemek mümkün olacaktır.

$\mathrm{Bu}$ çalışmanın sonucunda laboratuvar uygulamalarından oluşan bir etkinlik programının, öğretmenlerin laboratuvar kullanımına 
yönelik özyeterlik inançlarını $\operatorname{arttırdığı~ortaya~konulmuştur.~}$ Öğretmenlerin laboratuvar kullanımına yönelik özyeterlik inançlarındaki yükselişin, onların laboratuvar kullanma davranışlarına nasıl yansıdığı bu araştırmada konu edilmemiştir ancak sonraki araştırmalarda incelenmesinin önemli olduğu düşünülmektedir. Çünkü ilgili araştırma sonuçları olumlu özyeterlik inancına sahip kişilerin, isteyerek harekete geçtikleri ve daha az stresle daha başarılı olduklarını göstermektedir (Kurbanoğlu, 2004; Y1lmaz, Gürçay, \& Ekici, 2007). Ayrıca kişinin becerileri konusundaki inançlarının sadece davranışlarını değil, motivasyonunu ve başarısını da etkilediği ifade edilmektedir (Bandura, 1977; 1986; Henson, Kogan, \& VachaHaase, 2001). Buradan yola çıkarak çalışmada ulaşılan sonuçların bundan sonra gerçekleştirilecek olan ilgili çalışmalara kaynak teşkil etmesi beklenmekte bununla beraber laboratuvar kullanımına yönelik özyeterlik inancının, öğretmenlerin motivasyonları ve başarıları ile arasındaki ilişkilerin incelenmesi ile daha bütüncül sonuçlara ulaşılabileceği düşünülmektedir.

\section{Kaynaklar}

Akkuş, H. \& Kadayıfçı, H. (2007). “Laboratuvar kullanımı” konulu hizmet-içi eğitim kursu ile ilgili bir değerlendirme. Gazi Eğitim Fakültesi Dergisi, 27 (1), 179-193.

Ayas, A., Çepni, S., \& Akdeniz, A. R. (1994). Fen bilimleri eğitiminde laboratuvarın yeri ve önemi-II. Çăgdaş Ĕ̈itim, 205, 7-11.

Aydoğdu, C. (1999). Kimya laboratuvar uygulamalarında karşılaşılan güçlüklerin saptanmas1. Hacettepe Üniversitesi Ĕ̈itim Fakültesi Dergisi, 15, 30-35.

Bandura, A. (1977). Self-efficacy: toward a unifying theory of behavioral change. Psychological Review, 84, 191-215.

Bandura, A. (1986). Social foundations of thought and action: A social cognitive theory. Englewood Cliffs, NJ: Prentice-Hall.

Bandura, A. (1994). Self efficacy. In V. S. Ramachaudran (Ed.). Encylopedia of human behavior (Volume 4, pp. 71-81). New York: Academic Press. http://www.uky.edu/ eushe2/Bandura/BanEncy.html\#top

Bandura, A. (1995). Self-efficacy in changing societies. Cambridge: Cambridge University Press.

Böyük, U., Demir, S., \& Erol, M. (2010). Fen ve teknoloji dersi öğretmenlerinin laboratuvar çalışmalarına yönelik yeterlik görüşlerinin farklı değişkenlere göre incelenmesi. TÜBAV Bilim Dergisi, 3 (4), 342-349. 
D. Kılıç, Ö. Keleş... / Ë̈U Eğitim Fakültesi Dergisi,17(1) (2015), 218-236

Büyüköztürk, Ş., Atalay, K., Sozgun, Z., \& Kebapçı, Ş. (2011). The development of research self-efficacy scale. Cypriot Journal of Educational Sciences, 1, 2229.

Cohen, J. (1988). Statistical power analysis for the behavioral sciences, 2. Edition, New Jersey: Lawrence Erlbaum Publishers.

Çalışkan, S., Selçuk, G. S., \& Özcan, Ö. (2010). Fizik öğretmen adaylarının özyeterlik inançları: cinsiyet, sınıf düzeyi ve akademik başarının etkileri. Kastamonu Ĕ̈itim Dergisi, 18 (2), 449-466.

Çepni, S., Kaya, A., \& Küçük, M. (2005). Fizik öğretmenlerinin laboratuvarlara yönelik hizmet içi ihtiyaçlarının belirlenmesi. Türk Ĕgitim Bilimleri Dergisi, 2 (3), 181-196.

Delcourt, M., \& Kinzie, M. (1993). Computer technologies in teacher education: Theeducation: the measurement of attitudes and self-efficacy. Journal of Research and Development in Education, 27, 31-37.

Ekici, G. (2009). Biyoloji öğretmenlerinin laboratuar kullanımı öz-yeterlik algılarının incelenmesi. Ahi Evran Üniversitesi Ĕ̈itim Fakültesi Dergisi, 10 (3), 25-35.

Garnett, Patrick J., \& Garnett, Pamela J. (1995). Refocussing the chemistry lab: a case for laboratory-based investigations. Australian Science Teachers Journal, 41 (2), 26-32.

Güneş, H. M., Şener, N., Topal Germi, N., \& Can, N. (2013). Fen ve teknoloji dersinde laboratuvar kullanımına yönelik öğretmen ve öğrenci değerlendirmeleri. Dicle Üniversitesi Ziya Gökalp Eğitim Fakültesi Dergisi, 20, 1-11.

Henson, R. K., Kogan, L. R., \& Vacha-Haase, T. (2001). A reliability generalization study of the teacher efficacy scale and related instruments. Educational and Psychological Measurement, 61 (3), 404-420.

Hofstein, A., \& Mamlok-Naaman, R. (2007). The laboratory in science education: the state of the art. Chemistry Education Research and Practice, 8, 105-107.

Kocakülah, A., \& Savaş, E. (2011). Fen bilgisi öğretmen adaylarının deney tasarlama ve uygulama sürecine ilişkin görüşleri. Ondokuz Mayıs Üniversitesi Eğitim Fakültesi Dergisi, 30 (1), 1-28.

Kotaman, H. (2008). Özyeterlilik inancı ve öğrenme performansının geliştirilmesine ilişkin yazın taraması. Uludă̆ Üniversitesi Eğitim Fakültesi Dergisi, 21 (1), 111-133.

Kurbanoğlu, S. S. (2004). Öz-yeterlik inancı ve bilgi profesyonelleri için önemi. Bilgi Dünyası, 5 (2), 137-152.

MEB (2013). Fen Bilimleri Dersi (3, 4, 5, 6, 7 ve 8. Sinıflar) Öğretim Programı. Talim ve Terbiye Kurulu Başkanlığı. Ankara. 
Nakiboğlu, C., \& Sarıkaya, Ş. (2000). Kimya öğretmenlerinin derslerinde laboratuvar kullanmalarına mezun oldukları programın etkisi. Kastamonu Ë̆itim Dergisi, 8 (1), 95-106.

Şeker, R.,Yalçın, M., \& Yurdanur Altunay, A. (2006). Öğrencilerin kullanımına açık merkez fen laboratuvarları kurulması önerisi ile ilgili ögrenci, ögretmen ve veli görüşleri. VII. Ulusal Fen Bilimleri ve Matematik Eğitimi Kongresi Bildiriler Kitabı. Ankara: MEB.

Uluçınar, Ş., Cansaran, A., \& Karaca, A. (2004). Fen bilimleri laboratuvar uygulamalarının değerlendirilmesi. Türk Eğitim Bilimleri Dergisi, 2, 465475.

Yaman, S., Cansüngü Koray, Ö., \& Altunçekik, A. (2004). Fen bilgisi öğretmen adaylarının öz-yeterlik inanç düzeylerinin incelenmesi üzerine bir araştırma. Türk Eğitim Bilimleri Dergisi, 3 (2), 355-366.

Yener, D., Aydın, F., \& Köklü, N. (2012). Genel fizik laboratuvarındaki öğrencilerin fiziğe karşı öz-yeterliklerine animasyon ve simülasyonun etkisi. Abant İzzet Baysal Üniversitesi Eğitim Fakültesi Dergisi, 12 (2), 121-136.

Yılmaz, M., Gürçay, D., \& Ekici, G. (2007). Akademik özyeterlik ölçeğinin Türkçeye uyarlanması. Hacettepe Üniversitesi Eğitim Fakültesi Dergisi, 33, 253-259.

\section{Extended Summary}

\section{Purpose}

The current study aims to investigate the effect of the activity program called "Laboratory Applications for Science and Technology Teachers" on teachers' self-efficacy beliefs regarding the use of the laboratory. For this purpose, the study seeks answer to the question "Do the teachers' self-efficacy beliefs about the use of the laboratory vary significantly following the application of the program?"

\section{Method}

In the current study, one of the semi-experimental research models, single group pretest-posttest model was employed to determine cause and effect relationships between the variables. As the activity program developed within the current study needs to be implemented in a single group due to its purpose and content, single-group design was selected and thus the effect of the program on the teachers' self-efficacy beliefs about the use of the laboratory was investigated. In line with the research model of the current study, pretest and posttest were administered to reveal the effect of the applied program on the teachers' selfefficacy beliefs regarding the use of the laboratory.

The study group consists of 60 science teachers participating in the program of "Laboratory Applications for Science and Technology Teachers". In selection of the participants for the program, those who have some difficulties in using the laboratory and conducting experiments required by the teaching program 
and having graduated from one of the departments of science, physics, chemistry or biology teaching were preferred. Of the total 261 teachers applying to participate in the program, 60 teachers fulfilling the criteria were selected to make up the study group. The participants are working in state schools located in 20 different cities of Turkey.

Within the context of the activity program called "Laboratory Applications for Science and Technology Teachers”, laboratory experiments recommended in the curriculum of natural sciences course were conducted by the academicians. Throughout the five-day program, totally 44 experiments were conducted within 36 class hours. Before the experiments, the necessary theoretical information was presented by the instructors and then with individual or group participation depending on the content of the experiment, the experiments were conducted.

In order to investigate the participants' self-efficacy beliefs about the use of the laboratory, "Laboratory Use Self-efficacy Perception Scale” was used. The scale consists of 18 five-point Likert type items. In the current study, for the whole of the scale, reliability value calculated through Cronbach's alpha coefficient was found to be 0.87 .

In order to determine whether the participants' self-efficacy beliefs varied significantly after the application, dependent samples t-test was run to test the significance of the difference between the mean scores. Cohen $d$ value was calculated for the effect size and then reported.

\section{Results}

As a result of the analysis of the descriptive statistics conducted, it was found that the difference between the pretest mean score of the participants ( = $73.73)$ and their posttest mean score $(=79,35)$ is 5.62 . In order to test the statistical significance of this difference, dependent samples t-test was run and it was found to be statistically significant $(\mathrm{t}(59)=-4.374 ; \mathrm{p}<0,001)$. The effect size of this difference was calculated to be as Cohen $d=0.56$. This value indicates a medium effect size. In light of these results, it can be claimed that laboratory applications program increased the participants' self-efficacy beliefs regarding the use of the laboratory.

\section{Conclusion and Discussion}

In the current study, the effect of the activities carried out within the framework of laboratory applications program on the science teachers' self-efficacy beliefs regarding the use of the laboratory was investigated. The results of the analysis showed that the laboratory applications program increased the participants' test scores for the use of the laboratory and thus contributed to their self-efficacy beliefs. It was concluded that the participants' self-efficacy beliefs improved after the implementation of the laboratory applications program.

As a result of the analysis of the data collected in the present study, the difference between the pretest and posttest scores was found to be significant and 
D. Kılıç, Ö. Keleş... / Ë̈ Ĕ̆itim Fakültesi Dergisi,17(1) (2015), 218-236

this shows that the participants' self-efficacy beliefs about their capacity to conduct the experiments got stronger after the implementation of the program. Related literature has reported that individuals perform some activities and then they evaluate the outcomes of these activities, based on these evaluations, they develop a self-efficacy belief about performing similar activities and then they act depending on their self-efficacy beliefs.

It is clear that effective implementation of laboratory applications is of great importance for the accomplishment of the objectives of science education. Thus, the laboratory utilization skills and knowledge of science teachers need to be developed and updated. In line with the findings of the current study, it can be argued that programs similar to the one developed in the current study should be offered to science teachers continuously so that they can learn how to conduct experiments through new approaches and simple materials. Such programs should focus on practice rather than theoretical information, and then they can make important contributions to the development of teachers' self-efficacy beliefs regarding the use of the laboratory. 